\title{
Valoración, partición y distribución de la tierra de los resguardos indígenas en una localidad andina venezolana. Santa Bárbara de Chachopo/
}

\author{
Assessment, Partition and Distribution of Indian reserve land \\ in a Venezuelan Andean locale: Santa Barbara de Chachopo
}

\author{
Edda O. Samudio A.
}

Universidad de Los Andes, Mérida, Venezuela

El artículo examina el proceso mediante el cual los Resguardos indígenas que fueron establecidos en la región andina venezolana en el tardío siglo XVI experimentaron su disolución tres centurias más tarde. El objetivo central de este trabajo es analizar la valoración, partición y distribución de esos Resguardos Indígenas de Mérida, tratando de apreciar la intervención de los factores que participan en ese hecho; para el estudio de los aspectos contemplados en el proceso de extinción de las tierras que fueron otorgadas, con carácter común e intransferible, a los pueblos de indios de Mérida; en esta ocasión, se tomó como ejemplo el caso de Santa Bárbara de Chachopo.

Palabras Clave: Santa Bárbara de Chachopo; Mérida; Andes Venezolanos; Resguardos; Valoración; Comunidades indígenas; Distribución.

The article examines the process of the establishment of Indian reserves (resguardos) in the Venezuelan Andes in the late sixteenth century, and the experiences of their dissolution three centuries later. The main objective of the study is to analyze the appraisal, partition and distribution of the Indian reserves of Merida, assessing the role of the factors that were key elements in that process. The study includes aspects of the extinction of lands that were given with common and non-transferable title to the Indians settlements of Merida. The case of the pueblo of Santa Barbara de Chachopo is here offered as an example.

KeYwords: Santa Barbara de Chachopo; Merida; Venezuelan Andean; Indian Reserves; Assessment; Partition; Indian Communities; Distribution. 


\section{Introducción}

En la Nueva Granada, a cuya jurisdicción estuvo adscrita Mérida hasta 1777 , se denominó Resguardo a las tierras asignadas a los pueblos de indios con carácter comunal e inalienable, mientras en otros territorios andinos, el área adjudicada a las comunidades indígenas, se conoció simplemente como tierras de comunidad, en tanto que en México esta propiedad fue conocida como Fundo Legal. ${ }^{1}$ Sin embargo, de manera general, en las provincias neogranadinas, no así en Mérida, el término Resguardo fue asociado a pueblo de indios, es decir que se identificaba la propiedad comunal con el propio poblado. ${ }^{2}$ Por su parte, en la provincia de Venezuela, a la que fue anexada Mérida en lo gubernamental, en aquel año del siglo XVIII, el término Resguardo indígena fue adoptado en el siglo XIX y su uso, de manera extendida y concreta, se hizo ostensible en la legislación republicana.

De hecho, estos espacios destinados a las comunidades indígenas formaron parte de ese proceso de ordenamiento espacial ${ }^{3}$ que instituyó la Corona española en sus territorios de Ultramar, por medio del cual incorporó compulsivamente la población indígena a la trama de su control político, económico y social. ${ }^{4}$ Sin embargo, muy pronto, en esas áreas a las que se limitó la existencia indígena entraron en pugna costumbres y valores ancestrales con los recién impuestos, cuya asimilación y dominación no resultó una labor fácil, ni plena. Por el contrario, esos espacios se constituyeron en núcleos generadores de resistencia a las agresiones a las tierras comunales, la que se manifestó a través de una diversidad de procedimientos o tácticas, las cuales se enfrentaban a medidas y estrategias dominadoras.

La lucha de los indígenas por conservar sus tierras comunales, elemento esencial en la existencia de la comunidad aborigen, fue una evidente expresión de oposición a la agresión generada a lo largo del tiempo colonial, particularmente en las últimas décadas coloniales y en el periodo republicano, provocada por los intereses crecientes de una sociedad con vocación individualista liberal de la propiedad de la tierra que se impuso

1 Gerhard, 1975, p. 576; Licate, 1981, pp. 118-119.

2 Solano, 1990, p. 343.

3 Sobre ordenamiento espacial véase Duncan, 1990, p. 17; Herrera Ángel, 1966.

4 Foucault, 1979, considera el ordenamiento espacial como un instrumento eficaz al servicio del sistema político. 
finalmente en el siglo XIX tardío sobre la propiedad comunal indígena; ésta tuvo su expresión jurídica en un cuerpo de leyes promulgadas en esa centuria.

En las transformaciones que experimentó la propiedad comunal indígena, si bien la legislación republicana fue un componente eficaz y diligente, es preciso considerar los agentes externos, corporativos e individuales, como artífices de las modificaciones que sufrieron los pueblos de indios y, por ende, de la desestructuración de los resguardos. La presencia progresiva de población mestiza y otra serie de avecindados en los asentamientos indígenas fueron diluyendo paulatinamente la dualidad indio-no indio y dando paso a sociedades locales multiétnicas. ${ }^{5}$

Aquella población radicada en los asentamientos de resguardos, con derechos de tierra de labor, arrendataria o simplemente domiciliada en el poblado, compartía con los nativos los espacios comunales; situación que, de acuerdo a la máxima autoridad provincial de Mérida, provocó tal caos en esos pueblos por “... la anarquía, inseguridad y litigios en que se hallan envueltos los individuos que han comprado y están comprando subrepticiamente tierras de resguardos". ${ }^{6}$ Para resolver aquel desconcierto, el mismo funcionario proponía tomar medidas drásticas que culminaran con la división de las tierras comunales.

Así, las incomodidades que experimentaban los pueblos de indios, no sólo provenían de los avecindados, sino también de atropellos de los acomodados propietarios de las unidades de producción circunvecinas, los que originaron una cadena de quejas y reclamaciones ante las autoridades de turno, sin lograr, en un buen número de casos, eco alguno. Tal realidad permite comprender hasta donde las leyes decimonónicas imbuidas por los aires de "modernidad liberal", destinadas a la división y repartición de los resguardos fueron efectivamente factor desestructurador de la propiedad comunal. De hecho, ese proceso tenía antecedentes de vieja data, circunstancia que no significa desconocer que las disposiciones legales republicanas sobre la propiedad comunal incidieron en la presencia y acción de agentes foráneos, ni como elementos de presión para aligerar y obligar a reducir el patrimonio comunal a parcelas en manos de pequeños propietarios.

Definitivamente, las leyes liquidadoras del resguardo venezolano y, en particular, en el andino merideño, propiciaron la participación de otros sec-

5 Al respecto véase Escobar Ohmstede, 1996, pp. 1-24.

6 Memorias Provinciales. 1845, 1973, p. 271. 
tores de la sociedad en esos territorios, presionaron su partición, dando formalidad legal a ese hecho y a la posesión de las individualidades enmarañadas, destino final de esos espacios; hecho que debió satisfacer a sus gestores, quienes buscaban a toda costa y bajo la bandera de los nuevos ideales liberales, el libre desarrollo de nuevas fuerzas productivas. ${ }^{7}$ Sin lugar a dudas, no se puede soslayar el papel de la legislación decimonona, generadora de cambios, agente efectivo de presión e instrumento pautador en la liquidación de la propiedad colectiva de la tierra.

Ciertamente, la propiedad comunal incompatible con las ideas ilustradas constituía un obstáculo en el desarrollo de los proyectos económicos liberales expresados abiertamente desde el siglo XVIII y planteados formalmente en el XIX, cuando las nuevas repúblicas hispanoamericanas ${ }^{8}$ hicieron suyo el proyecto desamortizador y liquidador de bienes inmuebles. Así, con los inicios de la vida republicana, desde México ${ }^{9}$ a la Argentina, se manifestaron frontalmente las reformas anticorporativas. ${ }^{10}$

En efecto, la propiedad comunal no encajaba en la concepción individualista de la sociedad, ni con los principios económicos liberales que sustentaban que la propiedad plena e individual de la tierra y el libre juego de los factores económicos, eran elementos esenciales en la efectiva y significativa productividad. De tal manera que, los miembros de esas aldeas pasarían a ser "pequeños propietarios", tal como lo había planteado Rousseau, ${ }^{11}$ defensor de la división de las tierras comunales. Así, buena parte de esos lugares se convirtieron en una conjunción de minifundios, mientras otros fueron absorbidos e incorporados a propiedades privadas aledañas, dando origen a una propiedad mayor, la propugnada por los fisiócratas. De cualquier manera, con grandes desventajas, la población trabajadora de estos poblados y sus tierras fueron arropadas por el sistema socioeconómico imperante.

En los últimos años, los análisis sobre el Resguardo han representado importantes avances — particularmente en México- con trabajos, entre otros, como los de John Tutino, Jean Meyer y Raymond Buve, ${ }^{12}$ y en algunos países andinos como los de Langer y Luis Miguel Glave, ${ }^{13}$ Erwin

7 Samudio A., 1998.

8 Martínez de Codes, 1996, p. 146.

9 Hamnett, 1985, pp. 152-158.

10 Levaggi, 1998.

11 Rivera Sierra, 1985, p. 805.

12 Tutino, 1990; Meyer, 1984; Buve, 1996.

13 Langer, 1991; Bonilla (comp.), 1991: Glave, 1992. 
Grieshaber y Guerrero ${ }^{14}$, y el de de Solano de las Aguas - Flórez Bolívar, referido a Colombia. ${ }^{15}$ En Venezuela el tema ha sido poco estudiado ${ }^{16} \mathrm{y}$ en el caso andino venezolano, ${ }^{17}$ todavía queda mucho por hacer, cuyo estudio se apoya en una importante información documental recabada particularmente en los expedientes sobre repartos de los resguardos de Mérida que se conservan en el Registro Principal de la misma ciudad. Igualmente, se contó con el apoyo de información bibliográfica y hemerográfica, que constituyen un soporte fundamental, tanto en el aspecto teórico como metodológico. Los resultados que se presentan forman parte de un proyecto de investigación más amplio y ambicioso sobre el tema.

El objetivo central de este trabajo es analizar la valoración, partición y distribución de los Resguardos Indígenas de Mérida, tratando de apreciar la intervención de los factores que participan en ese hecho; para el estudio de los aspectos contemplados en el proceso de extinción de las tierras que fueron otorgadas, con carácter común e intransferible, a los pueblos de indios de Mérida, en esta ocasión, se tomó como ejemplo el caso de Santa Bárbara de Chachopo.

Se estima que el proceso de partición de las tierras comunales indígenas merideñas no fue un hecho homogéneo sino que cada caso presenta particularidades, a pesar de que también existen importantes similitudes. En la división de esos terrenos intervinieron y se conjugaron, en forma diversa, factores humanos y naturales.

Asimismo, se considera que la liquidación del Resguardo en Mérida fue la culminación de un proceso que se inició con su establecimiento y se dinamizó con las modificaciones que experimentaba la sociedad influida por el espíritu racionalista de la Ilustración y los valores sustentados por los principios individualistas del avasallador y emergente liberalismo económico, que tuvo en la propiedad de la tierra y la fuerza laboral indígena elementos fundamentales para el logro de sus objetivos.

14 Grieshaber, 1991 y del mismo autor, 1980; Guerrero, 1992.

15 Solano de las Aguas y Flórez Bolívar, 2007.

16 Han tratado el tema de estudio: Amodio: "Invasión y defensa de los resguardos en el Oriente de Venezuela, 1770-1850”, 1991; Samudio A., 1997 y 1999: Valdés, 1974; Rodríguez Rojas, en www.monografias.com.

17 En torno al conocimiento del Resguardo indígena en Mérida se han producido en un tiempo relativamente reciente algunos aportes, producto de un seminario que se inició en la Facultad de Humanidades y Educación en 1979 y que continúa siendo motivo de investigación: Entre ellos: Varela D. y Toro, 1988; Sandia M. y Contreras, 1991. 


\section{Aspectos geosociales}

Santa Bárbara de Chachopo está asentada en el valle alto y longitudinal del río Motatán, en un cono torrencial y en terrazas, a 2.600 m.s.n.m., ${ }^{18}$ con una temperatura media anual de $11.4^{\circ} \mathrm{C}$ y precipitación media anual de $975 \mathrm{~mm}$. Esta localidad es la capital de la parroquia Andrés Eloy Blanco, nombre del ilustre poeta venezolano que hizo de esta población andina un paraje y un motivo en su poesía. Su vegetación es predominantemente de páramo, de gramíneas y arbustos.

Para 1846, la localidad de Chachopo, hoy cabecera de la parroquia Andrés Eloy Blanco del Municipio Miranda, contaba con una población de 612 habitantes de legendaria tradición agrícola. En ese entonces, esta parroquia, que estaba en la jurisdicción del Cantón Mucuchíes de la provincia de Mérida, tenía el $8 \%$ del total de agricultores de las siete entidades parroquiales del cantón.

En 1873, el primer censo nacional atribuye a la parroquia de Chachopo del Departamento Miranda del Estado Guzmán, 773 individuos distribuidos entre el poblado y los caseríos o partidos, sectores del Resguardo, de La Pueblita, Campo Alegre, La Venta y Piedra Gorda, a cargo de comisarios. No obstante, cuatro años más tarde, en 1877, su población, que se calculaba en seiscientos individuos, se discriminó en 400 indios "puros", 100 mestizos y 100 blancos "puros", lo que no sólo significa que la mitad de la población no era comunera, ${ }^{19}$ sino que la parte indígena perdía importancia ante el fenómeno del mestizaje, circunstancia favorecida por la presencia de una población no indígena en los pueblos de resguardos y el desplazamiento de los nativos hacia las zonas productoras y estimuladas por el auge de la economía del café.

En 1881, a Chachopo le estiman 770 habitantes y diez años más tarde, el censo de 1891 asigna al municipio Chachopo del Distrito Campo Elías del Estado Los Andes, 772 personas, ${ }^{20}$ crecimiento definitivamente nulo o estancado, según los datos censales referidos.

Un siglo después, de acuerdo al censo de población de 1990, Chachopo contaba con 1.681 habitantes, dedicados particularmente a la agricultura. Orientada a la producción de tubérculos y hortalizas, con la uti-

18 Vivas, 1992, p. 154.

19 Jáuregui, 1948, pp. 56-57. También en Estados de Venezuela, 1988, p. 22.

20 Tercer Censo Nacional 1891. Caracas, 1891, T. IV, p. 39. 
lización moderada de maquinaria agrícola, suministro de riego y aplicación de abonos, que complementan con cierta actividad ganadera. En los últimos años sus habitantes tendieron a desarrollar la floricultura, sin embargo, el cultivo de la papa y las hortalizas ocupan la mayor parte de las tierras cultivables y su población económicamente activa se concentra mayoritariamente en la actividad aerocomercial. ${ }^{21}$

Chachopo se encuentra a 64 Kilómetros de Timotes, capital del Municipio Miranda, y a 105 kilómetros de Mérida; las dos primeras localidades, por sus rasgos orográficos, conforman una microrregión que se comunicaba con Mérida, hasta la apertura de la carretera trasandina, a través del riesgoso desfiladero del Alto Motatán, ${ }^{22}$ por donde atravesaba el angosto camino real de herradura o mulero interandino que relacionaba a Mérida con Trujillo, con el que Chachopo mantenía importantes relaciones comerciales. ${ }^{23}$

En el plano de partición de los resguardos de 1890, se aprecian cambios en la circulación por el poblado; uno de ellos es el desuso del camino nacional antiguo o camino real que los chachopenses reconocen como carretera trasandina y hoy es una simple calle que bordea por su parte superior el área de los antiguos ejidos y que las personas mayores de la localidad denominan actualmente con el nombre de Sequión. ${ }^{24}$

En la actualidad, el tránsito automovilístico se hace por las avenidas principales de Chachopo. Se atraviesa el pueblo subiendo, rumbo a Mérida por la avenida Santa Bárbara o de la Iglesia, mientras se baja por el lado oeste de la plaza, correspondiente a la actual avenida Bolívar. Además, del pueblo partían caminos vecinales de herradura que lo comunicaban con poblaciones aledañas como Palmira, Santo Domingo, Pueblo Llano y Piñango.

Espacios como el destinado al cementerio, debidamente identificado e inmediato al área ejidal en el plano de partición, hoy día se encuentran prácticamente abandonados. De acuerdo a informantes del lugar, el campo-

21 Chachopo, 1983, p. 2.

22 Comentarios sumamente interesantes sobre las comunicaciones en la región andina venezolana, en Cunill Grau, 1987, T. II, pp. 1035-1036.

23 Sobre esas relaciones para el año 1877, Jáuregui, 1948, pp. 54-57.

24 Entre esas personas estuvo don Ramón Rivas, quien con sus 84 años recuerda con claridad hechos y nombres que ayudan a localizar y clarificar algunos topónimos y a conocer aspectos interesantes de la vida cotidiana de Chachopo. Estos vecinos señalan que aquel camino se junta con el de abajo, después de pasar por la quebrada Tibuque, conocida como Los Caracoles, por el oeste, y antes de llegar a la quebrada Mucunantú por el este. 
santo antiguo resultaba pequeño para la población, por lo que algunos parroquianos solicitaron que se les concediera otro terreno para la construcción de un nuevo cementerio. Este fue inaugurado hacia 1940, porque el antiguo se encontraba completamente colapsado. No obstante, el segundo resultó igualmente pequeño, circunstancia que ha determinado al habilitar de nuevo el viejo camposanto, construido en $1855 .{ }^{25}$ En los sesenta, ambos cementerios estaban en uso, pues no se había abandonado aún el viejo recinto

Las tierras frías de Chachopo permitieron el desarrollo de una importante actividad triguera en la zona; ya maduro el grano, se segaba con hoces y atado en gavillas era transportado a caballo o en burros hasta las eras para secarlo y luego trillarlo en forma rudimentaria; luego se trasladaba el grano a los tres molinos hidráulicos que existían en Chachopo en los años setenta del siglo XIX y donde se obtenía la conocida harina criolla.

También, las tierras frías chachopenses permitieron a sus pobladores el cultivo de papas, maíz, arbejas, habas, señalándose que los terrenos propicios para la agricultura eran los de Piedra Gorda, Mufique, Pedregal y, particularmente, en La Venta y El Llano. La actividad agrícola la complementaron con la cría de vacunos, caballos y burros, ovejas, cabras, cerdos o marranos y gallinas.

Las cifras de producción de 1877 revelan el predominio de cultivos anuales, lo que significa que las tierras de labor de la parroquia fueron dedicadas principalmente a la producción de trigo y papas; hecho que muestra que el trigo había desplazado prácticamente los tradicionales paisajes maiceros. La agricultura se practicaba con técnicas e instrumentos rudimentarios: además de las treinta yuntas de bueyes que arrastraban el arado de madera, medio principal de preparar la tierra para la siembra — aún utilizado en la zona-, las hachas, escardillas, hoces, machetes, coas, calabazas y barras eran los frecuentes utensilios de labranza. ${ }^{26} \mathrm{El}$ peso del trabajo de la tierra, desarrollado en faenas diarias de hasta once horas, lo llevaba el cabeza de familia, quien tenía que hacer frente a las necesidades fundamentales de la prole y la disponibilidad de peones estaba definida por la capacidad de pago del patrón, mano de obra que no abundaba y a quienes, además de los quince céntimos diarios, se les proporcionaba pan de maíz y de trigo, arbejas, frijoles, papas, queso y panelas. No obstante, la mano de obra

25 Jáuregui, 1948, p. 57.

26 Ibidem. 
empleada en las labores agrícolas provenía frecuentemente de común convite o "mano vuelta", que consistía en la colaboración con carácter retributivo de los vecinos a las faenas del campo, sin pago de salario o bien se recurría al sistema de medianería, ${ }^{27}$ ya señalado. Pero la naturaleza comunitaria abarcaba la colaboración en diversas formas, existiendo un préstamo frecuente de utensilios domésticos y de trabajo. También a través del convite se llevaron a cabo obras de carácter comunal, como arreglo de caminos y mantenimiento de acequias, entre otras.

\section{La propiedad comunal indígena en Mérida en el siglo XIX}

A partir de las últimas décadas del siglo XVIII y primera mitad del XIX ocurrieron importantes transformaciones sociales de los pueblos de indios de Mérida, que han sido atribuidas de manera particular a un reacomodo de esos pueblos ante las presiones sociales ejercidas en esa atmósfera de "modernidad liberal" ${ }^{28}$ En el caso de los pueblos de Mérida, al igual que en otras ciudades andinas, los registros parroquiales de los últimos lustros coloniales conservan testimonios de la participación de indígenas forasteros y miembros de otras etnias en los hechos sacramentales, quienes lograron acceso a la tierra comunal a través del arriendo y la compra-venta de derechos, constituyéndose en condueños del usufructo en esos espacios comunales. Así, en las últimas décadas de dominio hispánico, la presencia de una población forastera avecindada en forma permanente trajo consigo la intensificación de los procesos de mestización, circunstancia que marcó diferencias sustanciales con los siglos anteriores. Desde entonces, esos asentamientos se constituyeron en receptores de una población no indígena, circunstancias que acentuaron progresivamente su heterogeneidad socio cultural. Además, la elevación de unos pocos de esos pueblos de doctrina a parroquias y, sobre todo, su reducida población tributaria a la Corona, dejaron a sus autoridades tradicionales - caciques y principalessin el cumplimiento de una importante función comunal, relegando su poder y significación social, hecho que se acentuó después de la

27 Se define como un contrato entre el dueño de la tierra y el aparcero, quien trabaja "a medias", comprometiéndose a cultivarla y a repartirse equitativamente la producción; en estos casos la tierra se cede en aparcería a medianeros o medieros. Problemas Económicos y Sociales de Los Andes, T. I, pp. 144-145.

28 Escobar Ohmstede, 1996. 
Independencia, con el establecimiento del nuevo orden político-territorial $\mathrm{y}$, consecuentemente, el nombramiento de nuevas autoridades locales.

Lo antes expuesto permite plantear que el proceso de desmadejamiento de la propiedad comunal que culmina con su partición individualizada o particularizada, estuvo estrechamente vinculado al de las transformaciones que experimentaron internamente los pueblos de resguardo. Estas, en buena medida, se atribuyen a agentes externos presentes en el escenario pueblerino, los que generaron, entre otras cosas, un verdadero caos dentro de la propiedad comunal que culminó con la definitiva parcelación de esas tierras, mediante un proceso legal, lento y engorroso, que hizo además palpable la existencia de una estratificación social pueblerina. Se reconoce que la Guerra de Independencia fue un componente de peso en la desbandada experimentada por la población indígena y el desconcierto sobre sus resguardos.

Desde la primera mitad del siglo XIX se acentuaron las modificaciones en los asentamientos indígenas; a los cambios en la estructura política del antiguo régimen con el establecimiento del nuevo orden y la afluencia paulatina de forasteros a los pueblos de resguardos, se sumaron consecuentemente los continuos arriendos y la adquisición progresiva de derechos en las tierras de los poblados.

La propia situación interna de las comunidades indígenas y la de su realidad contigua, como la presión que debieron ejercer las medidas legales que en forma exigente estuvieron destinadas a la liquidación de la propiedad comunal, debieron motivar el estado de confusión y el comportamiento hasta contradictorio que se producía en su interior. Al mismo tiempo que los comuneros se resistían al reparto de tierras, “... urgidos algunos indígenas o por su pobreza o por sus inveteradas costumbres empeñan y enajenan las suertes que poseen como usufructuarios, resultando infaliblemente de esta pecaminosa corruptela un semillero de pleitos y una confusión complicada entre los individuos que han vendido porciones, entre quienes las han tomado y entre los que se han abstenido de disponer de sus posesiones", ${ }^{29}$ lo cual no sólo implicó la ampliación de las tierras ocupadas por foráneos, sino una progresiva y compleja segmentación de sus tierras cultivables, definidas territorialmente con cercas y otros hechos, algunos de índole geográfica.

29 Memoria del Gobernador de Mérida dirigida a la Diputación Provincial. Mérida, 1 de septiembre de 1845. Memorias Provinciales, 1973, p. 271. 
Aquella práctica se vio favorecida por el desplazamiento de los nativos hacia distintas zonas del territorio, particularmente a las atractivas tierras de cultivo de café y caña de azúcar, por compra o a través del vínculo matrimonial.

Ciertamente, las escrituras notariales sobre transacciones de terrenos de los resguardos, muestran casos en que ya se evidencia la transferencia de la propiedad de una porción de tierra o sea que además compartían modalidades de propiedad plena, hecho que llama la atención, pues la tenencia de estos terrenos funcionaba con base en usufructo y posesión y, por tanto, no se transfería la propiedad de la tierra, sino el derecho a su provecho o goce. En esa forma, el espacio comunal indígena, esencia de la naturaleza corporativa, fue cediéndole terreno al individualizado, con la consecuente fragilidad de usos, costumbres y valores ancestrales.

Seguramente, esa población que formó parte de los grupos migrantes y colonizadores de las tierras recién roturadas en el Estado, contribuyó a garantizar los peones de aquellas haciendas y, particularmente, el trabajo en unidades de producción más pequeñas, las que mantenían una agricultura permanente y relativamente intensiva. Sin embargo, en los pueblos de resguardo se conservó una población diligente, protagonista del fraccionamiento formal del Resguardo, en la que está, en parte, el origen de la pequeña propiedad o minifundios, aún característica de algunas zonas de las tierras andinas merideñas.

De esa manera, la legislación que determinaba que las tierras comunales fueran distribuidas y otorgadas en forma individual, completa, libre y circulante, constituyeron un importante y decisivo ingrediente dentro del proceso de descomposición que estaba en marcha, presionando su división y legalizando la partición que dio legitimidad a una patente realidad social que se había plasmado en individualidades embrolladas en esos espacios comunales. Así, ellas legitimaron pasos, instrumentos y estrategias, mediante los cuales la propiedad colectiva de los pueblos de Mérida pasó a propiedad individual.

El proceso de parcelación de las tierras comunales se inició en Mérida a partir de los años treinta del siglo XIX, con San Antonio de Tabay, capital del actual municipio Santos Marquina, para ese entonces pueblo del cantón capital y del primer circuito judicial de Mérida, cuyas tierras comunales se encontraban entre los 1.750 y los $3.200 \mathrm{~m}$. y el cual se acogió a lo establecido en la Ley del 2 de abril de 1836. Mientras otras localidades, como La Mesa, con resguardos que se encontraban entre los 
780 a $2.120 \mathrm{~m}$. de altitud, seguramente menos presionada por las circunstancias o más renuente a liquidar su propiedad comunal, se encontraba cumpliendo las trámites finales del juicio de partición en las postrimerías del siglo XIX.

\section{Juicio de Partición del Resguardo Indígena de Santa Bárbara de Chachopo}

De manera general, el proceso de liquidación de la propiedad comunal se iniciaba con la solicitud del juicio de partición del resguardo, al que se anexaba el título que probaba su dominio, posesión y propiedad; petición que estaba a cargo de uno de los comuneros o de un funcionario público, tal como ocurrió en el caso que nos ocupa. Seguidamente eran establecidos los linderos del resguardo, solucionando los problemas legales pertinentes, y se procedía a la publicación del emplazamiento público, doce veces consecutivas. Este requisito se llevaba a cabo con el objeto de que llegara a conocimiento de todos los comuneros, particularmente de aquellos que habitaban fuera del poblado en el momento de la iniciación del juicio. Luego se procedía a nombrar la Junta encargada de realizar, primeramente, el censo de la población indígena y, después, el registro de los individuos ajenos a la comunidad que habían adquirido derechos en las tierras comunales. Se debe señalar que cuando algún indígena, hombre o mujer, estaba casado con forastero, se asentaba su nombre, pero no se le concedía derecho alguno.

Posteriormente, se realizaba el avalúo de las tierras comunales, al que seguía la división, distribución y, por último, su aprobación. Esta le concedía carácter definitivo y legal, pues debía ser aceptada por todos los comuneros, o sea miembros de la comunidad con plenos derechos a la tierra y a la participación en su división y adjudicación, reconocida judicialmente por la autoridad competente.

En los años ochenta se dio comienzo al juicio de partición de los resguardos de Chachopo, cuando el poblado apenas tenía 1.653 individuos. El proceso se inició el 15 de julio de 1884, al hacerse presente el fiscal nacional, Pedro María Febres Cordero, representante del Gobierno en los juicios de partición en el Estado Los Andes, ante el juez de Primera Instancia en lo Civil de Mérida, quien, acogiéndose a la Ley de junio de ese mismo año, pedía que se diera cumplimiento a lo establecido en la referida Ley sobre 
la división de los resguardos de Chachopo, para entonces parroquia del Distrito Miranda de la sección Guzmán. El fiscal debía intervenir en cada uno de los actos del juicio, por lo que nombró como su auxiliar a Sebastián Arriaga, quien lo representaría en su ausencia.

Seguidamente, el citado juez comisionó al juez de Parroquia de Chachopo, Manuel Montilla, para que practicara todas las diligencias de sustentación del juicio de partición de los terrenos pertenecientes a la comunidad de indígenas de esa jurisdicción parroquial y mientras, el fiscal nacional oficiaba al mismo juez de Parroquia, ${ }^{30}$ a habilitar el tiempo de la vacación para no interrumpir el juicio, atento a que todavía no se había terminado el padrón de los interesados, en el que debían figurar no sólo los indígenas, sino también los no indígenas o vecinos que poseyeran con justo títulos de terrenos de los resguardos. Además, solicitaba que finalizado el censo se citase a la comunidad y a los vecinos o a sus respectivos apoderados, si los hubiere, para que manifestaran su conformidad con la división solicitada y en consecuencia se procediera al nombramiento del perito valuador y medidor de los terrenos y el partidor que haga la distribución conveniente en la inteligencia. Asimismo disponía que, previamente a la medición de las tierras, se expresara el alindamiento bajo el cual las han tenido los indígenas desde tiempos remotos. También advertía que los vecinos poseedores presentasen los documentos para acreditar la posesión que tenían dentro del resguardo.

El 24 de agosto de 1884, José María Rivas, primera autoridad civil de la parroquia, Manuel F. Montilla, juez de la parroquia, y Juan Bautista Ramírez, jefe y procurador municipal, certificaban que los linderos que constituían la comunidad, por no tener los títulos originales, eran los conocidos antiguamente según escrituras de posesiones particulares contiguas a dicho resguardo y reconocidos por espacio de treinta años. En este acto que contó con la presencia y el consentimiento de la totalidad de los indígenas de la parroquia se definieron los límites señalados, tal como se puede advertir en la Figura 1.

Sin embargo, tres días antes de la presentación del fiscal nacional, Pedro María Febres Cordero, algunos indígenas y vecinos de la parroquia concedieron un poder ilimitado a Pablo Pissani para que los representara y

30 El juez de Parroquia convocó la habilitación de la vacación, le tomó juramento al fiscal auxiliar y dispuso que, terminado el padrón de los partícipes, se citara a estos para informarles de todo y hacer los nombramientos que les correspondían. 


\section{FIGURA 1}

PLANO DE PARTICIÓN DE LOS RESGUARDOS

DE INDÍGENAS DE CHACHOPO. 1890

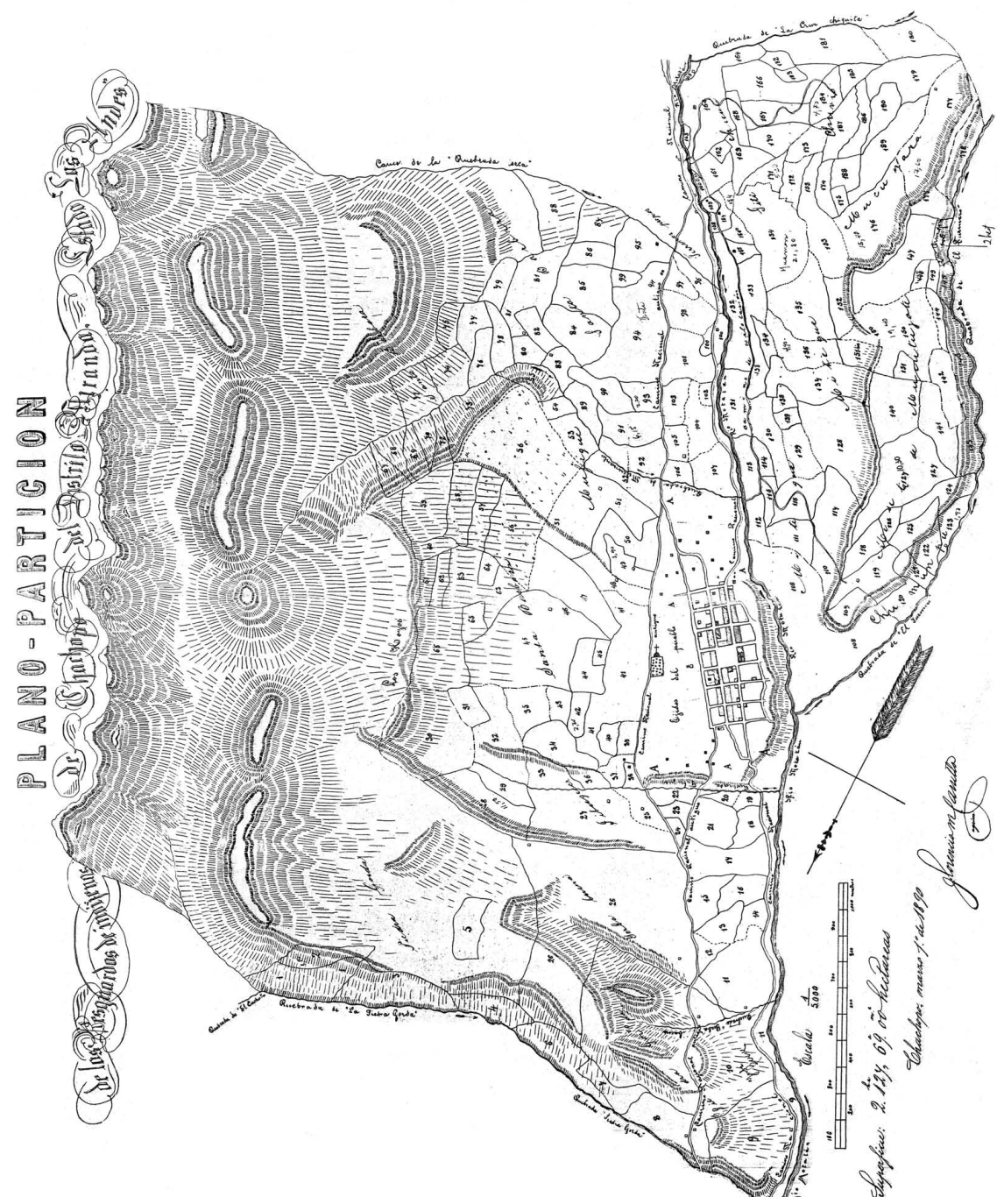

Fuente: Registro Principal de Mérida. PLANO-PARTICIÓN. De los Resguardos de Indígenas de Chachopo del Distrito Miranda. Estado Los Andes. Chachopo, marzo 1. ${ }^{\circ}$ de 1890. 
sostuviera sus derechos ante los tribunales y demás funcionarios públicos y corporaciones competentes, en el asunto sobre el reclamo de terrenos que como indígenas les pertenecían. ${ }^{31}$

Para entonces, ya deslindado el área que correspondía al resguardo, los comuneros habían otorgado poder a Marcelino Rodríguez, secretario del Juzgado de la Parroquia, para que les representara en el juicio. ${ }^{32}$ Este funcionario representante y defensor de los indígenas en el juicio de partición y el fiscal nacional, representante del gobierno, habían nombrado como medidor y único perito evaluador de los terrenos divisibles a José Jesús Quintero, vecino de Mérida, quien debía entregar al partidor el resultado de la medida y avalúo de esos terrenos, labor que culminó el 23 y entregó el 24 de septiembre, o sea nueve días después de su nombramiento, atestiguando que el resguardo medía novecientas hectáreas, en las que se incluían 27 de ellas destinadas al plano de la población; igualmente, aquellos nombraron partidor a don Pedro de Jesús Godoy o en su defecto al doctor Foción Febres Cordero.

Apenas habían transcurrido dos meses de iniciado el Juicio de Partición del Resguardo de Chachopo cuando se produjo su paralización, hecho nada extraño en estos procesos judiciales. Y en este caso, como en otros similares, su suspensión se atribuye a la derogación de la Ley de división de los Resguardos de Indígenas del 16 de junio de 1884, al sancionarse la del 25 de mayo de 1885 y luego, a trastornos políticos en el Estado.

El juicio que se inició legalmente en junio de 1884, se reinició tres años más tarde, el 19 de julio de 1887, con la exposición del apoderado de los indígenas sobre lo acontecido y pidiendo al juez de Primera Instancia continuar la demanda formal de partición que debía llevarse a cabo de acuerdo a las prescripciones de la nueva Ley, la de mayo de 1885 . El mismo funcionario solicitaba la publicación en la prensa del libelo para que comparecieran los que consideraban tener derecho a participar en el juicio; además, señalaba el nombramiento de curador, quien representaba a los partícipes que lo requerían, y se comisionaba al juez de Parroquia de Chachopo para que interviniera en todas las diligencias de

31 Registro Principal de Mérida. Protocolos 2, 3 (Tercer) Tomo. Escritura de poder de los indígenas de Chachopo a Pablo Pissani. Timotes, 12 de julio de 1884. ff. 1v.-2.

32 Se localizó otro poder otorgado por algunos vecinos a Marcelino Rodríguez en el mismo sentido, es decir, para que los represente y defienda sus derechos en el juicio de partición de los resguardos de Chachopo. Ibidem. Escritura de Poder. Timotes, 9 de julio de 1887. ff. 1v-2. 
sustanciación hasta que el expediente fuera al Tribunal de Mérida para su aprobación definitiva; debía inclusive atender la reforma del padrón que ya se había levantado; el nombramiento de agrimensor y el de partidor y peritos, al igual que la aprobación o revisión de la partición por los interesados.

La acción total de reparto fue valorada en más de ocho mil bolívares, pues el valor de las tierras excedía ese monto; los gastos de la partición serían abonados en proporción a los derechos adjudicados por todos los partícipes en dinero. Para hacer las prorratas y recolectarlas se nombró al señor Juan Nepomuceno Castillo, quien no aparece registrado entre los comuneros, ni los vecinos.

En el expediente se encuentran los doce emplazamientos que se publicaron en el Registro de Anuncios, por no haber periódico oficial y ser éste el de circulación más regular en la Mérida de entonces; los emplazamientos fueron publicados entre julio y octubre de 1887. ${ }^{33}$ También en las escrituras hay la constancia de fijación de carteles, medio utilizado para hacer conocer a todo el vecindario de la parroquia la iniciación del juicio de partición y, así, que los interesados concurrieran a inscribirse. Se hizo el nombramiento de los miembros que debían constituir la Junta para formar el padrón de las familias comuneras, integrada por el jefe civil, el procurador municipal y dos vecinos, tal como lo preveía el Artículo 5..$^{\circ}$ de la última Ley sobre Resguardos Indígenas.

En cuanto al padrón, ${ }^{34}$ el registro familiar permitía el conocimiento del número de miembros por familia, junto al de huérfanos menores de edad e incapaces, lo que facilitaba la división. Así, el padrón revisado y

33 El 25 de julio de 1889, al estar hechas las doce publicaciones por la prensa que previene la ley y transcurridos los diez días y el término de distancia legal que señala el auto de comparecencia del tribunal después de la última publicación, se presentó el apoderado demandado, general Evaristo Méndez, como apoderado de varios indígenas y vecinos de Chachopo, informando que convenía que se procediera a la partición de las tierras conforme a lo establecido en la ley vigente. El juez declaró terminado el acto, reservándose disponer en decreto separado la formación del padrón que expresase por familias los individuos componentes de dicha comunidad y lo relativo al nombramiento de peritos, agrimensor, partidor y curador de los indígenas que aparecen como huérfanos menores. Registro Principal de Mérida. Juicio Divisorio de los Resguardos de Indígenas de Chachopo...ff. 27-38.

34 El padrón concluye con las firmas de Daniel del Carmen Acevedo, jefe civil de Parroquia, Manuel Mantilla, procurador municipal, y las firmas de Manuel Volcanes, Venancio Ramírez y Félix Ramírez. Los tres primeros fueron vecinos adjudicatarios en el Resguardo Volcanes, siendo nombrados peritos evaluadores de los terrenos del Resguardo el 28 de noviembre de 1889. Los dos últimos están en la lista de los indígenas. El 6 de noviembre de 1890, Félix Ramírez Carrillo fue nombrado curador especial de los menores indígenas y demás incapaces pertenecientes a la comunidad de estos Resguardos. Ibidem, $55-55 \mathrm{v}$. 
conocido que se realizó entre el diez de agosto de 1887 y el catorce de agosto de 1889, totalizó 144 familias con 776 individuos, los que comprendían tanto los comuneros que mantenían sus derechos, como aquellos que los habían cedido. Además, se consignaron los nombres de 27 no comuneros, quienes habían adquirido derechos en las tierras del pueblo; sin embargo, en la adjudicación de los lotes que culminó el primero de marzo de 1890, hubo 43 receptores y algunos de los que aparecen en la primera lista, tal como el familiar Marcelino Rodríguez, ya no estuvo entre los adjudicatarios.

El 6 de noviembre de 1889 se nombró y juramentó a Félix Ramírez Carrillo, uno de los comuneros, curador de los indígenas huérfanos menores e incapaces, quien los representaría en el juicio de partición; mientras Marcelino Rodríguez, apoderado demandante de los indígenas en el juicio, aparece en una lista entre los individuos que tenían parte en dicho Resguardo a título de compra o por cualquier otro concepto. Evaristo Méndez, apoderado demandado, y Félix Ramírez Carrillo, indígena, curador especial de los menores incapaces, en uso de las facultades que le confería la Ley nombraban a Florencio Carrillo, vecino de la ciudad de Timotes, agrimensor y partidor de las tierras comunales y quien unos días más tarde juró cumplir fiel y legalmente los deberes inherentes a su cargo. ${ }^{35}$ La mayoría de los adultos delegó legalmente su representación en un abogado para que defendiera sus derechos. Seguidamente, designaron y juramentaron a Manuel Volcanes, uno de los vecinos con intereses en el Resguardo, como perito evaluador de los terrenos, al igual que como testigo del avalúo a Rodolfo Quintero, otro de los vecinos intervinientes en la partición, y a Juan Polomidi. ${ }^{36}$

\section{Avalúo de los terrenos comunales}

Manuel Volcanes, Rodolfo Quintero y Juan Polomidi, perito y testigos del avalúo de las tierras comunales, asistidos por dos interesados en el juicio, teniendo en cuenta el conocimiento empírico sobre la calidad, situación y otras circunstancias, apreciaron y discriminaron su valor de la manera siguiente:

35 Ibidem., f. 56.

36 Ibidem., f. $56 \mathrm{v}$. 


\section{Cuadro 1}

AVALÚO DE LOS TERRENOS DEL RESGUARDO DE CHACHOPO.

2 DE DICIEMBRE DE 1889

Terrenos

Margen izquierda del río Motatán

Margen derecha del río Motatán

De Páramo
Valor/Bs./Hct.

$200,00 / 200$

160,00

Fuente: Registro Principal de Mérida. Caja. Juicio Divisorio de los Resguardos de Indígenas de Chachopo -1884-1887. Partición de los Resguardos de indígenas de Chachopo. 1887-1890. Partición de las Tierras de los Indios de La Parroquia de CHACHOPO. Distrito Miranda. Juzgado de 1era. Instancia en lo Civil. 1884-1889. Avalúo de los terrenos de los Resguardos de los indios de la Parroquia de Chachopo. 2 de diciembre de 1889. Se señalan de Páramo las tierras situadas al oriente de las de la margen izquierda del río Motatán, entre las líneas divisorias de las de labor y de cría y las demás del páramo en sus linderos.

El agrimensor público observó, entre otros asuntos, que los terrenos eran en su mayor parte cultivables, especialmente los situados a la orilla izquierda del río Motatán, mientras advertía que los de la margen derecha, los sectores más bajos y no muy inclinados, eran cultivados y cultivables. Al mismo tiempo, señalaba que el resto lo consideraba estéril y algunos sitios, aptos para la cría. A esta porción de los resguardos pertenecían los sitios de Santa Bárbara, Piedra Gorda, Yerba Buena, Tibuque, Mufique y La Venta. A más de ellos, los parajes de La Aguadita y Mistimabaque, en la parte más baja de Santa Bárbara, cerca de la margen derecha del río Motatán, mientras Muamantú se ubicaba en su sector más elevado.

Las tierras más apreciadas fueron las de la margen izquierda del río Motatán, las que comprendían los sectores de Miteque, Fití, Mucunaró, Chuvío, Mucutujote y Chumunpú que se extienden por el estrecho valle que forma la quebrada El Turmero, en el sector más bajo, hasta su desembocadura en el Motatán (Fig. 1). En efecto, la mayor estimación de esos terrenos la definió la orientación de solana de la margen izquierda del Motatán, porque la tierra de labor en las laderas más soleadas alcanza generalmente altitudes mayores. Además, se trata de laderas con áreas de menor pendiente, las que se recogen como Llano de Miteque, Llano de Chuvío y Llano de Fití. Entretanto, la margen derecha, en posición de umbría, recibe los rayos solares más tardíamente. Así, mientras en los primeros la hectárea fue valorada en 200 pesos, en la margen opuesta se le asignó sólo160 pesos (Fig. 1). 
A los páramos comprendidos entre la línea que separa los terrenos cultivables y los de cría, hasta las cumbres de la sierra que servía de lindero, por la parte oriental, se les asignó la cuarta parte del valor de la anterior, o sea 40 pesos. Advirtiéndose que, por deseo de los propios indígenas y, de acuerdo a la instrucción tercera, se dejaban 1.009,63 hectáreas de páramo más estéril para el beneficio exclusivo de los indígenas. Tácitamente, quedaban como partícipes en la comunidad del páramo todos los comuneros, inclusive aquellos que habían vendido o cedido sus derechos en las tierras repartibles, quienes debían "...ocupar personalmente y beneficiarse de la parte que puedan cultivar en proporción a los demás derechos, sin perjudicar los de los otros partícipes y según las demás reglas de la comunidad". ${ }^{37}$ Por supuesto, quedó asentado que los vecinos no tenían derecho alguno en esa área delimitada por la serranía, uno de sus linderos y los lotes que en las partes más elevadas habían sido ocupados o cercados. ${ }^{38}$

De hecho, en las zonas montañosas húmedas, a medida que aumenta la altitud, los paisajes cultivados van gradualmente cediendo a los pastizales; en Chachopo, al igual que en otros asentamientos emplazados en valles altos, la temperatura jugó un papel importante en la determinación de los límites entre las áreas repartibles y las de uso común, destinadas esencialmente a la cría. En el caso que nos ocupa se encuentran entre los $3.000 \mathrm{~m}$ y $3.200 \mathrm{~m}$ de altitud. A partir de esta altura, la frecuencia de heladas es una desventaja para la actividad agrícola. En la actualidad el páramo común, de acuerdo a los vecinos de Chachopo, es poco usado, pues aseguran que allí echaban su ganado a pastar, pero la cuatrería acabó con ello.

En Chachopo los terrenos relativamente planos son escasos; buena parte de ellos estaban ocupados por el poblado, por los ejidos y por terrenos destinados a la futura expansión del asentamiento.

Es importante resaltar que en la parcelación de los resguardos de Chachopo se definió claramente su ejido, espacio público heredado de la colonia que se caracteriza, como en este caso, por ser reserva de tierra de uso común que se encontraba próxima, pero fuera de la traza urbana. Sin embargo, se advierte que para el momento de la partición, en el área señalada como ejido existían alrededor de veinte viviendas o recintos particulares; hecho que bien podría estar relacionado con la ocupación y dominio individual que tiene en la actualidad.

37 Registro Principal del Estado Mérida, Caja, Juicio divisorio de los resguardos de indígenas del pueblo de Chachopo, 1884-1887.Petición hecha al agrimensor partidor, f. 59.

38 Ibidem, f. $57 \mathrm{v}$. 
De acuerdo al propio agrimensor, los ejidos tenían una extensión de 111,06 hectáreas, en las que se incluían las 25 hectáreas destinadas a la expansión futura de la población. Este sector, señalado en el plano con la letra $\mathrm{A}$, se orientó hacia los cuatro rumbos. "... la desembocadura de la quebrada Tibuque, primer lindero". ${ }^{39}$ No obstante, en una medición reciente, este área que corresponde a los ejidos no sobrepasa las 45 hectáreas.

\section{Partición o fraccionamiento del resguardo}

También, el 6 de diciembre de 1889, Marcelino Rodríguez, apoderado demandante, Evaristo Méndez, apoderado demandado, y Félix Ramírez, curador especial de los inhábiles, establecieron una serie de pautas que Florencio Carrillo, como agrimensor partidor, debía observar en la parcelación y adjudicación de los terrenos a los indígenas y vecinos partícipes. ${ }^{40}$ En primer término, tenía que tomar en cuenta la clasificación y valor de las tierras llevada a cabo previamente. Asimismo, debía señalar las quince hectáreas destinadas al aumento de la población, ensanchando el área primitiva, si fuese posible, en sus cuatro direcciones. Igualmente, tenía que mirar que los terrenos de páramos, o sea los que estaban comprendidos entre la línea que separaba los de cultivo y cría y las cumbres de la serranía que era el lindero oriental, quedaran exclusivamente para el beneficio de los comuneros, lo que significaba que los vecinos no tenían ningún derecho sobre ellos, aunque cualquier título les diese la condición de poseedores "seccionarios o adquirientes de derechos". ${ }^{41}$

También se le hizo conocer que se mantenían como límites de los resguardos los reconocidos en la primera etapa del juicio. Además, se estableció que los gastos de partición estuvieran en proporción a los derechos adjudicados y todos los partícipes cancelaran en efectivo, autorizándose a Juan Nepomuceno Carrillo el formar las prorratas y recolectar el dinero. Finalmente, se advirtió que para todo lo concerniente a la partición, el agrimensor partidor se entendiera con los apoderados.

De esa manera, el área total del resguardo, calculada por el medidor en 2.127, 69 hectáreas, tamaño que no se corresponde con el de la suma individual de las hectáreas adjudicadas a los lotes y tampoco con las mediciones

39 Ibidem.

40 Ibidem, fs. 57v.-58v.

41 Ibidem, f. 58. 
que hemos realizado. De cualquier modo, se estableció un área repartible o destinada al dominio individual o particular pleno y otra no repartible que fue consignada al uso común. Esta comprendía los ejidos del pueblo y los de comunidad del páramo que se conoce corrientemente como páramo común.

A cada lote repartible se asignó un número que comprendió del 1 al 190, pero constan 191 lotes, pues hubo un 151 bis; la numeración iniciada en la margen derecha del río Motatán, en Piedra Gorda, siguió rumbo a La Venta, dejando para el final el sector más cercano al río, donde llegó hasta el lote 107, o sea que mientras en el sector derecho estaban ubicados el 56 $\%$ de los lotes, en el izquierdo se encontraba el $44 \%$ restante, los cuales mantenían aproximadamente las mismas representaciones porcentuales en cuanto a superficie.

Los restantes ochenta y cuatro lotes de la margen izquierda del río empezaban por el 108, numeración que, de acuerdo al plano de partición, correspondía a Chumunpú; luego, la enumeración en forma ascendente se orientó hacia la quebrada de La Cruz Chiquita, límite sureste del resguardo. Según el citado plano de partición, el área de mayor y más regular fraccionamiento fue la margen izquierda del río Motatán.

Si tomamos en cuenta la medición del agrimensor, el área no repartible o de uso común representó el $52 \%$ de la superficie del resguardo. Esto significa que el $48 \%$ de las tierras comunales se consideró repartible y fue segregada para su reparto particular entre las familias con derecho, dividido en 191 lotes que se entregarían en propiedad a comuneros y vecinos con algún derecho sobre ellas.

La asociación de tamaño y ubicación de lotes muestra que los más grandes se señalaron en los sectores de mayor pendiente, mientras los más pequeños se concentraron en las zonas de menor declive, consecuentemente en conos de deyección y otros depósitos cuaternarios. Asimismo, se aprecia un cierto agrupamiento de lotes a lo largo de los cursos de agua, de la quebrada Tibuque o los Caracoles, la quebrada Mucunatnú y el río Motatán, en particular a su margen izquierda, como se ha señalado.

De acuerdo a información oral reciente y a testimonios de la época, en el área repartida ya existían cercamientos y viviendas. Asimismo, de las quince transacciones protocolizadas y localizadas de compra-venta de derechos que se dieron entre 1870 y 1890 , el $46 \%$ fue realizada por un morador de Timotes, capital de Departamento y sede del Registro, Eleodoro Carrillo, soltero y comerciante, de los "ricos" de la localidad. También entre los vendedores se encontraban vecinos de Timotes. Carrillo no sólo 
fue comprador de lotes, sino uno de los seis que más se beneficiaron con la partición de los terrenos comunales. Esta transferencia de la propiedad constituyó una expresión de los cambios en la tenencia de las tierras comunales y, consecuentemente, de su uso.

\section{Adjudicaciones de lotes}

De las 144 familias que totalizaban 776 individuos, entre adultos y menores, que constan en el padrón formado por la Junta de la comunidad de indígenas de la parroquia, tan sólo el $43 \%$ de ellas, compuestas por 377 personas que representan el $49 \%$ del total de la población comunera, participaron efectivamente en el reparto de los resguardos, mientras el $57 \%$ de las familias restantes y el $51 \%$ de la población comunera, no tuvieron adjudicación de tierras alguna, por haber enajenado o previamente cedido sus respectivos derechos. ${ }^{42}$ Asimismo, se adjudicaron lotes a 41 vecinos, ${ }^{43}$ quienes previamente habían adquirido derechos a través de la compra-venta. De esa manera, 103 cabezas de familia, entre comuneros y vecinos, participaron en la adjudicación de los 191 lotes o parcelas de las tierras repartibles. De ellas, el $40 \%$ fueron vecinos, a quienes se les adjudicó el $42 \%$ de los lotes y el $60 \%$ de indígenas recibió el $58 \%$ restante, con superficies muy similares. Seguramente, esta población se fue mezclando a través de matrimonios y, de esa manera, se acentuó el mestizaje en estas tierras.

No obstante, es importante destacar que mientras el promedio de hectáreas por vecino fue de 11.7 hectáreas, a cada indígena le correspondieron 1.45 hectáreas, aunque la familia comunera promedió 8.84 hectáreas. Si bien la asignación de lotes se hizo por familia indígena o comunera, en el registro de las adjudicaciones constaba el nombre de cada uno de sus miembros, tanto mayor como menor de edad, dada su condición de "derechantes" (poseedores de derechos).

Lo anterior significa que, además de haberse producido modificaciones en la tenencia de la tierra por efecto de la compra y venta de terrenos, igualmente contribuyó a ello el acaparamiento de la propiedad en el área. En este proceso participaron comuneros y personajes ajenos a la comunidad. Estos últimos desarrollaron particularmente una actividad comercial, vinculada al tradicional trabajo agrícola que caracterizaba a Chachopo.

42 Ibidem, f. $59 \mathrm{v}$.

43 Ibidem. 
Así, en el Cuadro 2 se presentan las seis mayores adjudicaciones a comuneros, que estuvieron en manos del $10 \%$ de familias de ese grupo, representando el total de sus miembros el $9 \%$ de población nativa. Este pequeño grupo de familias comuneras obtuvieron el $35 \%$ de las tierras asignadas a ellas y el $18 \%$ de todas los terrenos repartidos.

\section{CUADRO 2}

LAS MAYORES ASIGNACIONES DE TIERRA A COMUNEROS Y VECINOS EN LA PARTICIÓN DE LOS RESGUARDOS DE CHACHOPO. 1890

\begin{tabular}{lccc} 
Vecino & Hectáreas & Comunero (Familia) & Hectáreas \\
\hline Francisco Lobo & 49.90 & Jesús Ramírez & 38.35 \\
Ambrosio Salcedo & 43.60 & J.A. Ramírez & 33.90 \\
Ignacio Villamizar & 41.40 & Aniceto Carrillo & 31.60 \\
Miguel Carrillo & 37.15 & Juan A. Ramírez & 30.60 \\
Eleodoro Carrillo & 26.30 & M. M. Ramírez & 29.10 \\
Ricardo Lobo & 25.55 & Venancio Ramírez & 26.40 \\
\hline (6) Total & $223.90(53 \%)$ & $(6)$ & $189.95(45 \%)$
\end{tabular}

Fuente: Registro Principal de Mérida. Juicio Divisorio de los Resguardos de Indígenas de Chachopo. 1884-1887. Partición de los Resguardos de indígenas de Chachopo. 1887-1890.

Asimismo, las cifras expuestas ponen de relieve que tan sólo un $15 \%$ de los vecinos recibieron el $46 \%$ de las tierras asignadas a ese sector. Del total de tierras recibidas por ambos grupos, los más beneficiados fueron los vecinos, quienes se reservaron el $53 \%$ de ellas y entre ambos retuvieron el $40 \%$ de las tierras repartidas. Seguramente, algunos de ellos se involucraron en un débil sistema de aparcería.

Sin lugar a dudas, en el seno de aquellas comunidades, los cambios en la tenencia, el desarrollo de una actividad comercial, protagonizada por un restringido número de comerciantes en torno a la actividad agrícola y la presencia de unas pocas autoridades oficiales con jurisdicción parroquial marcaron una cierta estratificación social, lo que conllevaba la manifestación de diferencias en cuanto a prestigio, privilegios, obligaciones y comportamientos sociales y condiciones de vida.

De lo expuesto es posible derivar que en la interioridad de estos poblados se produjo una clara estratificación social, sin antecedentes en la comunidad indígena original, caracterizada por el surgimiento de un pequeño 
sector de "pudientes", dueños de terrenos que formaban el sector de "principales" del asentamiento, liderado por vecinos. Además, algunos de ellos eran propietarios de derechos de tierra en posesiones comuneras vecinas, tal como en Turmero y Miranda. Asimismo, se evidencia que en esta localidad, la autoridad del cacique, elemento clave en la comunidad, había perdido vigencia e igualmente se habían abandonado formas de la organización social con su estructura comunitaria a través de la cual había vínculos comunitarios, con la consecuente pérdida de valores, usos, costumbres y tradiciones.

La Figura 2, en la que se comparan las hectáreas asignadas a comuneros y vecinos de acuerdo a la distribución espacial en el área repartida a comuneros y vecinos, muestra que Santa Bárbara no sólo fue el sector de mayor extensión dentro de los adjudicados, sino donde hubo mayor número de participantes y se concedieron mayor número de lotes y de hectáreas a vecinos y comuneros.

\section{FIGURA 2}

\section{SUPERFICIE ASIGNADA POR SITIOS A INDÍGENAS Y VECINOS EN LA PARTICIÓN, 1890}

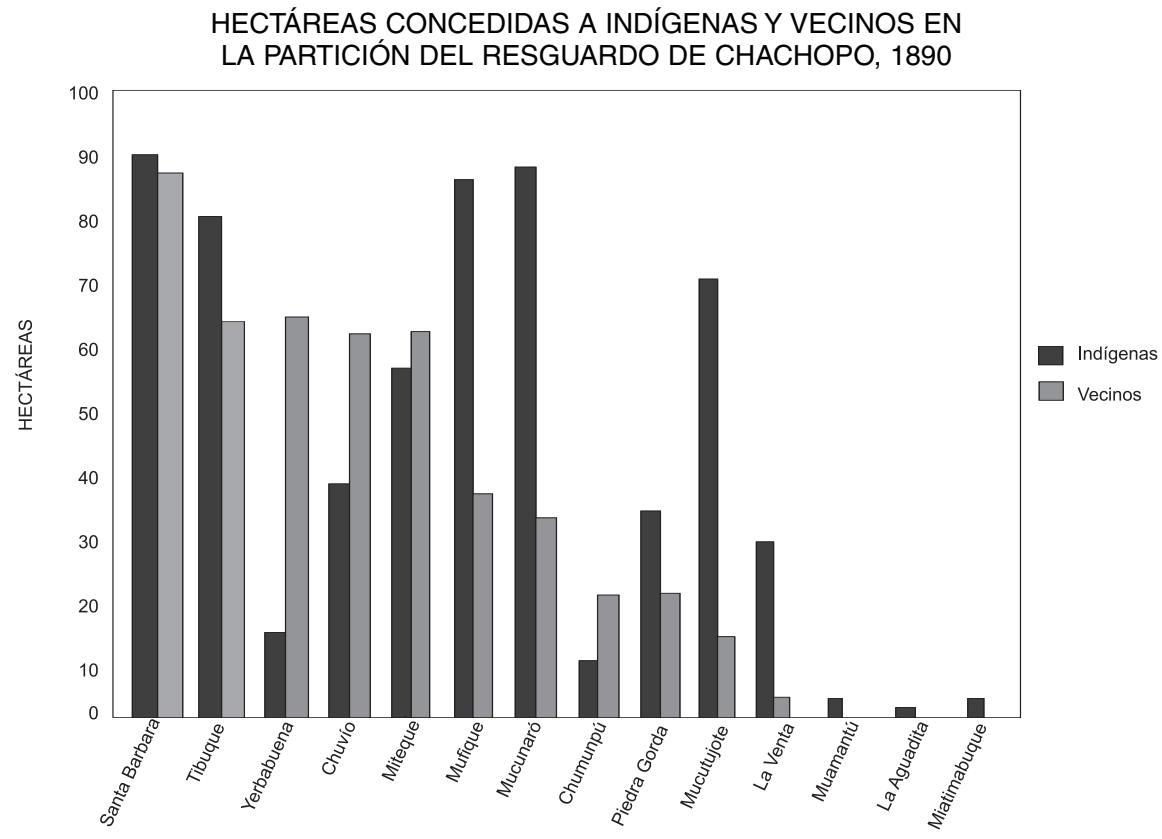


En ese mismo sector de la margen derecha del Motatán, las concesiones, en orden de importancia, se dieron en Tibuque y Mufique, en el caso de los indígenas, mientras los vecinos las obtuvieron en Yerba Buena y también en Tibuque. En esta sección de las tierras asignadas, los comuneros obtuvieron el 7.07 por familia, entre tanto, alcanzaron apenas el 1.06 hectáreas en forma individual; por su parte, la propiedad de los vecinos promedió 9.54 hectáreas.

Asimismo, la información analizada revela que la superficie asignada a los comuneros (60\% de los participantes) en las tierras de mayor valor, o sea a la margen izquierda del río Motatán, representó el $56 \%$, entretanto a los vecinos (40\% de los participantes) les correspondió el $44 \%$ de ellas. Mientras, los indígenas tuvieron mayor superficie en Mucunaró y Mucutojote, los vecinos lo lograron en Chuvío y Miteque, lugares más accesibles y cercanos al pueblo. Asimismo, mientras los comuneros promediaron 6.62 hectáreas por familia y escasamente 1.05 por comunero, los vecinos lograron individualmente 9.14 hectáreas.

La información sobre tamaño de las asignaciones a la familia comunera y a vecinos que muestra la figura siguiente, permite constatar que en el reparto de las tierras de Chachopo prevaleció una estructura minifundista, factor resaltante en las tierras altas merideñas y perturbador del desarrollo agrícola.

En la Figura 3 se comparan la representación de comuneros y vecinos respecto a las categorías de tamaño de las tierras asignadas, evidenciándose que las propiedades más pequeñas, las que no sobrepasaban las cinco hectáreas, fueron concedidas al $48 \%$ de los comuneros y al $49 \%$ de los vecinos; mientras al $24 \%$ y $19 \%$ de comuneros y vecinos se concedieron lotes cuya superficie oscilaba entre 5 y 10 hectáreas, respectivamente. Los datos expuestos ponen de relieve que en Chachopo, una población mayoritaria que alcanzó el $72 \%$ en el caso de los comuneros y el 68\% de los vecinos, se constituyó en propietaria de porciones de tierra que no sobrepasaban las 10 hectáreas, mientras el resto, significativamente menor, retuvo las mayores extensiones de tierra, sobresaliendo los vecinos que tuvieron una participación superior en las asignaciones de 35 y más hectáreas.

En la Figura 4 se compara la superficie de las asignaciones de tierra, en porcentajes, por categorías de tamaño que correspondió a comuneros y vecinos.

Finalmente, en el Gráfico 4 se confronta la superficie de las concesiones a comuneros y vecinos por tamaño de categorías. Éste muestra que 
EDDA O. SAMUDIO A.

FIGURA 3

REPRESENTACIÓN PORCENTUAL DE COMUNEROS Y VECINOS RESPECTO A LAS CATEGORÍAS DE TAMAÑO DE LAS ASIGNACIONES. 1890

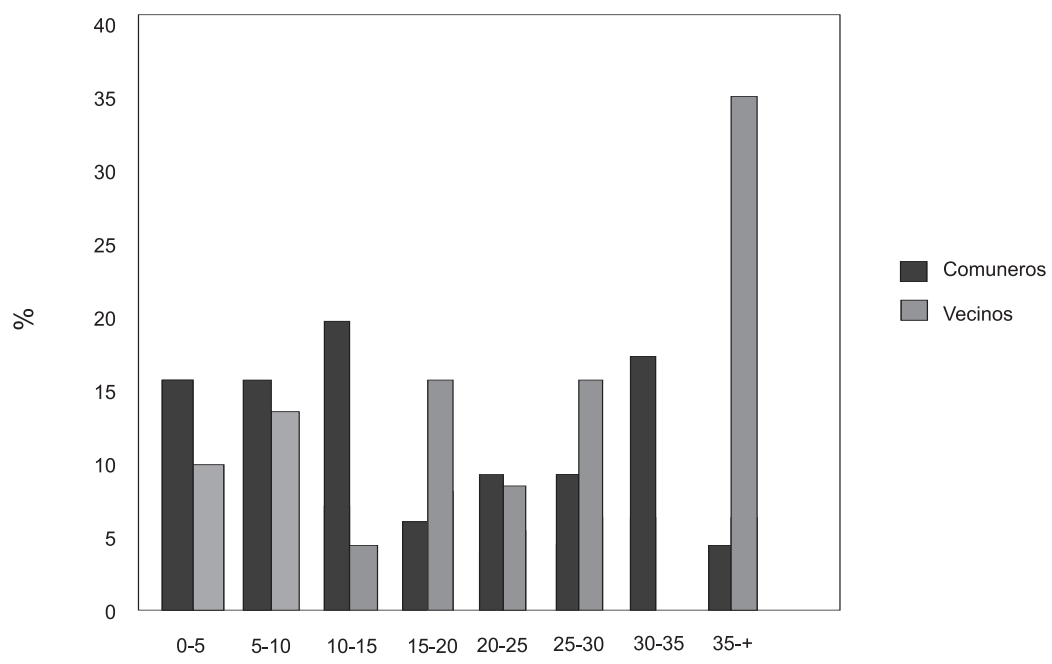

FIGURA 4

SUPERFICIE DE LAS CONCESIONES DE TIERRA POR CATEGORÍAS DE TAMAÑO A COMUNEROS Y VECINOS, 1890

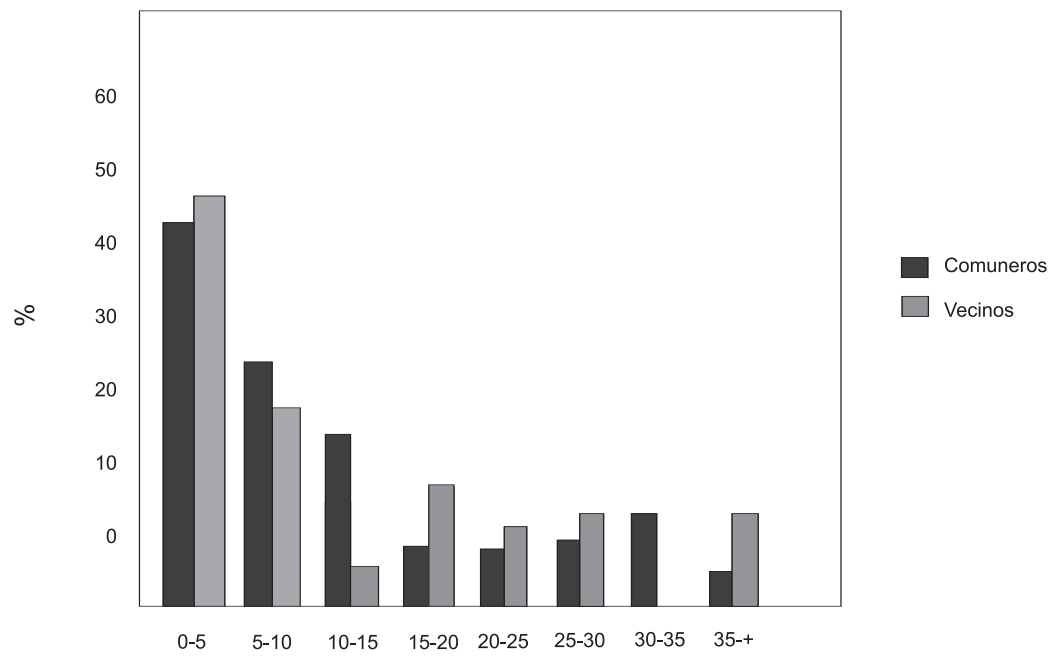


el $48 \%$ de comuneros y $49 \%$ de vecinos con propiedades por debajo de las 5 hectáreas, disponían apenas del $15 \%$ y $10 \%$, respectivamente, del total de la superficie otorgada a cada uno de ellos. Asimismo, el $24 \%$ de comuneros con lotes de 5 a 10 hectáreas compartía otro $15 \%$ de las tierras asignadas, mientras el $19 \%$ de vecinos tenía sus porciones de tierra de ese tamaño en el $13 \%$ del total de la superficie que les entregaron. De esa manera, el $72 \%$ de comuneros y $68 \%$ de los vecinos eran propietarios escasamente del 30 y $23 \%$ del total de las tierras repartidas a cada uno de ellos.

Asimismo, observamos que los vecinos dispusieron de mayor superficie en las categorías que superaban las quince hectáreas, a excepción de la leve diferencia entre las de 20 y 25 hectáreas y la no presencia de propiedades de vecinos en la categoría de 30 a 35 hectáreas. No obstante, dentro del $34 \%$ de las tierras de los vecinos se comprendían las posesiones superiores a 35 hectáreas; al mismo tiempo, el $10 \%$ de los comuneros con predios en esa categoría las tenían en escasamente el $6 \%$ del total de las tierras a ellos asignadas. De manera general, en el $49 \%$ de la totalidad de las tierras concedidas al $16 \%$ de los comuneros, estuvieron sus propiedades de más de 15 hectáreas, mientras el $29 \%$ de los vecinos las tuvieron en el $73 \%$ de sus terrenos.

\section{Consideraciones finales}

Desde la segunda mitad del XVIII, y particularmente en el siglo XIX, se acentúa la presencia de elementos ajenos a la comunidad indígena original, con la introducción inusitada de cambios en su estructura socio-económica que desnaturalizaron la razón de ser de la propiedad comunal o resguardos.

La legislación que disponía la individualización de las tierras comunales que se produjo en el siglo XIX, permite confirmar la hipótesis de que ellas, de ninguna manera, constituyeron precisamente elementos desestructuradores de las tierras comunales, aunque si resultaron ser un importante y decisivo ingrediente dentro del proceso de descomposición que estaba en marcha y que se acentuaba progresivamente.

La disolución del Resguardo en los valles merideños constituye, por tanto, el programado fraccionamiento de las tierras comunales, con la proscripción de su cultura y sistemas de producción, sustituidos por innovacio- 
nes propias de una economía basada en el desarrollo de la propiedad fundamentada en principios y valores de un individualismo propugnado por el naciente liberalismo, contrario al sentimiento y experiencia ancestral del indígena. Así, la política republicana se propuso eliminar la propiedad de las comunidades indígenas, aspirando a convertir a sus indigentes familias en pequeños y "productivos" propietarios y permitir que su mano de obra participara en el mercado laboral sin traba alguna.

De este modo, las leyes liquidadoras del resguardo venezolano y, en particular, en el andino merideño, propiciaron la participación de otros sectores de la sociedad en esos territorios, presionaron su partición, dieron formalidad legal a ese hecho y a la posesión de las individualidades enmarañadas, destino final de esos espacios; hecho que debió satisfacer a sus gestores, quienes buscaban a toda costa y bajo la bandera de los nuevos ideales liberales, el libre desarrollo de nuevas fuerzas productivas. De cualquier manera, con grandes desventajas, la población trabajadora de estos poblados y sus tierras fueron arropadas por el sistema socioeconómico imperante.

Así, buena parte de esos lugares pasaron a ser una conjunción de minifundios, mientras otros fueron absorbidos e incorporados a propiedades privadas aledañas, dando origen a una propiedad mayor, la propugnada por los fisiócratas.

En el estudio de los resguardos de Chachopo se encuentra el origen, razón y naturaleza de ese proceso de fraccionamiento de la tierra que experimentan todavía muchas zonas andinas, pues sus tierras, luego de repartidas, se siguieron subdividiendo cada vez que un núcleo familiar se atomizaba y nuevos herederos de una generación acentuaban el fraccionamiento, tan característico de los paisajes andinos venezolanos. Esta situación, asociada a la tradicional utilización de técnicas e instrumentos rudimentarios, la baja productividad del suelo y una reconocida dificultad y altos costos del transporte hasta los mercados, constituye, desde entonces, uno de los problemas socioeconómicos esenciales de estas tierras.

Otro de los rasgos negativos de ese proceso fue la transferencia de derechos de la tierra, a través de la compra-venta, situación que consecuentemente motivó la presencia de una población comunera no partícipe en la partición de las tierras, pues su condición de "derechante" había sido transferida a individuos generalmente ajenos a la comunidad y quienes pasaron "seguramente" a formar parte de esa importante población sin tierra, que desde entonces habita en las zonas altas merideñas. 
Los personajes foráneos, algunos de los cuales fueron los mayores propietarios de las tierras repartidas de Chachopo y se dedicaron al comercio, junto a unos pocos funcionarios públicos y a comuneros aventajados en el reparto de los resguardos, van a constituir la pequeña "elite" de esos asentamientos, muestra de que la estructura socioeconómica de esos poblados estaba distante a lo que había sido la comunidad original.

Finalmente, este estudio ofrece explicación a la propiedad mancomunada, a los derechos de páramo y de cría de las tierras andinas merideñas, vestigio de aquellos resguardos, pues ellos fueron parte de esas tierras comunales no repartibles que se dejaron para uso de los comuneros, a las que algunos de sus descendientes se apegan y apelan para mantener y usufructuar ese añejo derecho.

Recibido el 30 de junio de 2009 Aceptado el 12 de mayo de 2010

\section{Bibliografía}

Emanuel Amodio: "Invasión y defensa de los resguardos en el Oriente de Venezuela, 1770-1850", Montalbán, núm. 23, Caracas, 1991, pp. 267-308.

Heraclio Bonilla (comp.): Los Andes en la encrucijada, Indios, comunidades y Estado en el siglo XIX, Quito, Ediciones Libri Mundi-Flacso, 1991.

Raymond Buve: "Caciques, vecinos, autoridades y la privatización de los terrenos comunales: un hierro candente en el México de la República Restaurada y el Porfiriato", en Heraclio Bonilla y Amado A. Guerrero Rincón (eds.): Los pueblos campesinos de las Américas. Etnicidad, Cultura e Historia en el Siglo XIX, Bucaramanga, Universidad Industrial de Santander, 1996, pp. 25-41.

Chachopo. Informe. Mérida, Venezuela, Ministerio de Desarrollo Urbano, Dirección General Sectorial de Desarrollo Urbanístico, Octubre de 1983.

Pedro Cunill Grau: Geografía del Poblamiento venezolano en el siglo XIX, Caracas, Ediciones de la Presidencia de la República, 1987, T. II.

James Duncan: The City as a Text: The Politics of Landscape Interpretations in the Kandyan Kingdom, Cambridge, Cambridge University Press, 1990.

Antonio Escobar Ohmstede: "La conformación o no de una sociedad multiétnica en las Huastecas", Heraclio Bonilla y Amado A. Guerrero Rincón (eds.): Los Pueblos Campesinos de las Américas, Etnicidad, Cultura e Historia en el siglo XIX, 1996, pp. 1-24. 
Michel Foucault: Discipline and Punish. The Birth of the Prison, (1975), New York, Vintage Books, 1979.

Peter Gerhard: "La evolución del pueblo rural mexicano: 1519-1975", Historia Mexicana, vol. 24, No. 4, México, 1975, pp. 566-578.

Luis Miguel Glave: Vida, símbolos y batallas. Creación y recreación de la comunidad indígena. Cusco, siglos XII-XX, Lima, Fondo de Cultura Económica (FCE), 1992.

Erwin P. Grieshaber: "Survival of Indian communities in Nineteenth Century Bolivia: A Regional Comparison", Journal of Latin American Studies, Vol. 12, part. 2, Cambridge, november, 1980, pp. 223-269.

- "Resistencia indígena a la venta de tierras cumunales en el departamento de La Paz, 1881-1920", Tandeter, Grieshaber, Lander et al, Comunidades campesinas de los Andes en el siglo XIX, Data, n. ${ }^{\circ}$ 1, 1991, pp. 113-143.

Andrés Guerrero: La semántica de la dominación: el concertaje de indios, Quito, Ediciones Libri Mundi-FLACSO, 1992.

Brian R. Hamnett: La Política española en una época revolucionaria. 1790-1820, México, FCE, 1985.

Martha Herrera Ángel: Poder local, población y ordenamiento territorial en la Nueva Granada. Siglo XVIII, Bogotá, Archivo General de la Nación, 1966.

J. M. Jaúregui: Apuntes Estadísticos del estado Mérida, Mérida, Venezuela, Imprenta del Estado, 1948.

- Estados de Venezuela, Mérida, Venezuela, Banco Mercantil, Núm. 15, 1988.

Erick D. Langer: "Persistencia y cambio en las comunidades indígenas del sur de Bolivia en el siglo XIX", en Tandeter, Grieshaber, Langer y otros: Comunidades Campesinas de los Andes en el siglo XIX. Data, Núm. 1, 1991, pp. 61-81.

Abelardo Levaggi: "Ideología de la desamortización argentina del siglo XIX", en J. R. Fisher (ed.): Actas del XI Congreso Internacional de AHILA, Liverpool, Instituto de Estudios Latinoamericanos, Universidad de Liverpool, 1998, vol. III, pp. 187-200.

Jack Anthony Licate: Creation of a Mexican Landscape. Territorial Organization and Settlement in the Eastern Puebla Basin. 1520-1605, Chicago, University of Chicago, 1981.

Rosa María Martínez de Codes: "El programa carolino de reformas eclesiásticas. Evaluación de la política desamortizadora en América”, en VV.AA.: Homenaje al Profesor Alfonso García Gallo, T. III, Madrid, Editorial Complutense, 1996, pp. 145-165.

Memorias Provinciales. 1845. Recopilación y Prólogo de Antonio Arellano Moreno, Caracas, Ediciones del Congreso de la República, 1973.

Jean Meyer: "La desamortización de las comunidades en Jalisco", Esperando a Lozada, Zamora, Mich., El Colegio de Michoacán-CONACYT, 1984. 
Registro Principal de Mérida. Protocolos 2, 3 (Tercer) Tomo. Escritura de poder de los indígenas de Chachopo a Pablo Pissani. Timotes, 12 de julio de 1884. ff. 1vto-2.

- Juicio Divisorio de los Resguardos de Indígenas de Chachopo- 1884-1887. De Partición de los Resguardos de indígenas de Chachopo. 1887-1890. Consta de 62 folios.

- Caja, Juicio divisorio de los resguardos de indígenas del pueblo de Chachopo, 1884-1887. Petición hecha al agrimensor partidor, f. 59.

Jairo Rivera Sierra: "El Resguardo Indígena en la República. Una política y unas perspectivas", Boletín de Historia y Antigüedades, n. ${ }^{\circ} 751$, Bogotá, octubrediciembre, 1985, pp. 780-805.

Edda O. Samudio A.: "The Dissolution of Indian Community Lands in the Venezuelan Andes: The Case of La Mesa", Year Book 1997, Vol. 23, Austin, Texas, 1997, pp. 17- 26.

— "El Ocaso de las tierras comunales indígenas en la Mérida andina", Actas del XI Congreso Internacional de AHILA, 1998, T. III, pp. 289-306.

- "La Transformación de la propiedad comunal en Venezuela y Colombia a través del proceso de desvinculación de Bienes", Cuadernos de Historia Latinoamericana, No. 7, Netherlands, 1999, pp. 157-188.

Alba M. Sandia M. y Fany C. Contreras D: Resguardo de Bailadores: Una Liquidación Temprana. Tesis de Licenciatura en Historia. Mérida, Venezuela, Facultad de Humanidades y Educación, Escuela de Historia, 1991.

Sergio Paolo Solano de las Aguas y Roicer Alberto Flórez Bolívar: "Resguardos indígenas, ganadería y conflictos sociales en el Bolívar Grande, 1850-1875", en Historia Crítica, n. ${ }^{\circ}$ 34, Bogotá, julio-diciembre 2007, pp. 92-117.

Francisco de Solano: Ciudades Hispanoamericanas y Pueblos de Indios, Madrid, Consejo Superior de Investigaciones Científicas, 1990.

John Tutino: "Cambio social, agrario y rebelión campesina en el México decimonónico: el caso de Chalco", en Friedrich Katz (ed.): Revuelta, rebelión y revolución, México, Editorial Era, 1990, T. I, pp. 94-143.

Alberto Valdés: "La dotación de tierras a comunidades indígenas en Venezuela: desde la Colonia hasta nuestros días", América Indígena, Vol. XXXIV, No. 1, México, enero marzo 1974, pp. 215- 223.

Eglé Varela D. y Yoly Toro: Algunos aspectos de la Historia de Chiguará del siglo XVI al XIX, Tesis de Licenciatura en Historia. Mérida, Venezuela, Facultad de Humanidades y Educación, Escuela de Historia, 1988.

Leonel Vivas: Los Andes venezolanos. Caracas, Academia Nacional de la Historia / Italgráfica, 1992. 